\title{
Detection of human papillomavirus infection by non-isotopic in situ hybridisation in condylomatous and CIN lesions
}

\author{
R Pöllänen, S Vuopala, V-P Lehto
}

\begin{abstract}
Aims-To study the value of non-isotopic in situ hybridisation (NISH) in detecting human papillomavirus (HPV) infection in female genital lesions positive for the virus by conventional histology but negative by filter DNA hybridisation.

Methods-Forty three cases, which showed the histological hallmarks of the HPV infection but produced negative results in filter dot blot hybridisation tests (Vira Pap and Vira Type kits), were identified in the course of an investigation of 304 vaginal, vulvar, and cervical samples from 267 patients. These cases were studied by NISH for the presence of HPV infection.

Results-In 28 (65\%) of the cases NISH gave a positive hybridisation signal. In 26 cases $(96 \%)$ the signal was diffuse, and in two (4\%) punctate or diffuse, representing episomal and episomal or integrated HPV DNA, respectively. In most cases only a few HPV positive cells were discernible.

Conclusion-NISH is a more sensitive technique than dot blot hybridisation, detecting HPV infection in most cases which show histological HPV atypia but which remain negative in filter DNA hybridisation. Thus NISH is useful as an additional technique to verify the presence of HPV in lesions which remain negative in filter hybridisation tests.
\end{abstract}

(F Clin Pathol 1993;46:936-939)

Human papillomavirus (HPV) infection of the squamous epithelia is associated with typical cytopathic features which serve as classic hallmarks for the histopathological diagnosis. These include nuclear atypia and perinuclear halos (koilocytic cells). The histological diagnosis of HPV infection is fairly straightforward in the case of condylomatahighly differentiated epithelial lesions which usually present with distinct koilocytic atypia. In less well differentiated cervical and vulvar intraepithelial lesions (CIN II-III and VIN IIIII), the detection of lesions caused by HPV is much more problematic. This is due to the presence of increased mitotic activity and poor differentiation not only in the basal but also in the upper epithelial cell layers.

Evidence is accumulating for a close association between specific HPV types and female genital tract lesions. HPV 6 and HPV
11 are found mostly in condyloma acuminata while HPV 16, 18, 31, 33, and 35 are commonly seen in CIN lesions and in cervical carcinomas..$^{1-3}$ Moreover, the presence of HPV 16 in the cervix is of prognostic value because it seems to presage a progression from a mild to severe dysplasia and to carcinoma in situ. ${ }^{45}$ Therefore, not only the recognition of the HPV infection, but also the specific identification of the HPV type is important, because it may affect the assessment of the prognosis and the choice of the treatment and follow up modalities.

During the course of an investigation of 304 specimens from 267 patients for HPV infection we identified 43 cases which showed histological signs of HPV infection but which were negative for HPV DNA in dot blot hybridisation, using radioactively labelled probes (Virapap and Vira Type kits Digene Inc, Maryland, USA). These 43 samples were examined more closely for the presence of HPV DNA by non-isotopic in situ nucleic acid hybridisation (NISH) with HPV type specific probes. A recently described NISH signal categorisation system was also applied to assess whether HPV DNA is present in an episomal or integrated state. ${ }^{6}$

\section{Methods}

Biopsy specimens for routine histological examination were taken at colposcopy because of an abnormal finding from a Papanicolau stained smear (cases 2 to 4). They were fixed in $10 \%$ formalin and processed and embedded in paraffin wax using standard techniques. The sections were stained with haematoxylin and eosin and examined by a pathologist who was unaware of the DNA hybridisation results. The histological diagnoses of condylomata and CIN were made using generally accepted criteria. ${ }^{7}$

NISH was carried out using a Biohit HPV In Situ Screening and Typing Kit (Biohit Oy, Helsinki, Finland) for the paraffin wax embedded tissue blocks. The kit contains biotin labelled, type specific DNA probes for HPV types $6,11,16,18,31$, and 33 . The test was performed according to the manufacturer's instructions. Briefly, tissue sections were first dewaxed and hydrated and then digested with proteinase at $37^{\circ} \mathrm{C}$ for $15 \mathrm{~min}$ utes. After dehydration, the hybridisation probes were pipetted on the sections (20-40 $\mu 1 /$ section) which were then coverslipped and denatured at $+130^{\circ} \mathrm{C}$ for $10-12$ minutes. Hybridisation was carried out in a
Department of Patholog University of Oulu, Kajaanintie 52, D SF-90220 Oulu, Finland.

Accepted 3 June 1993 

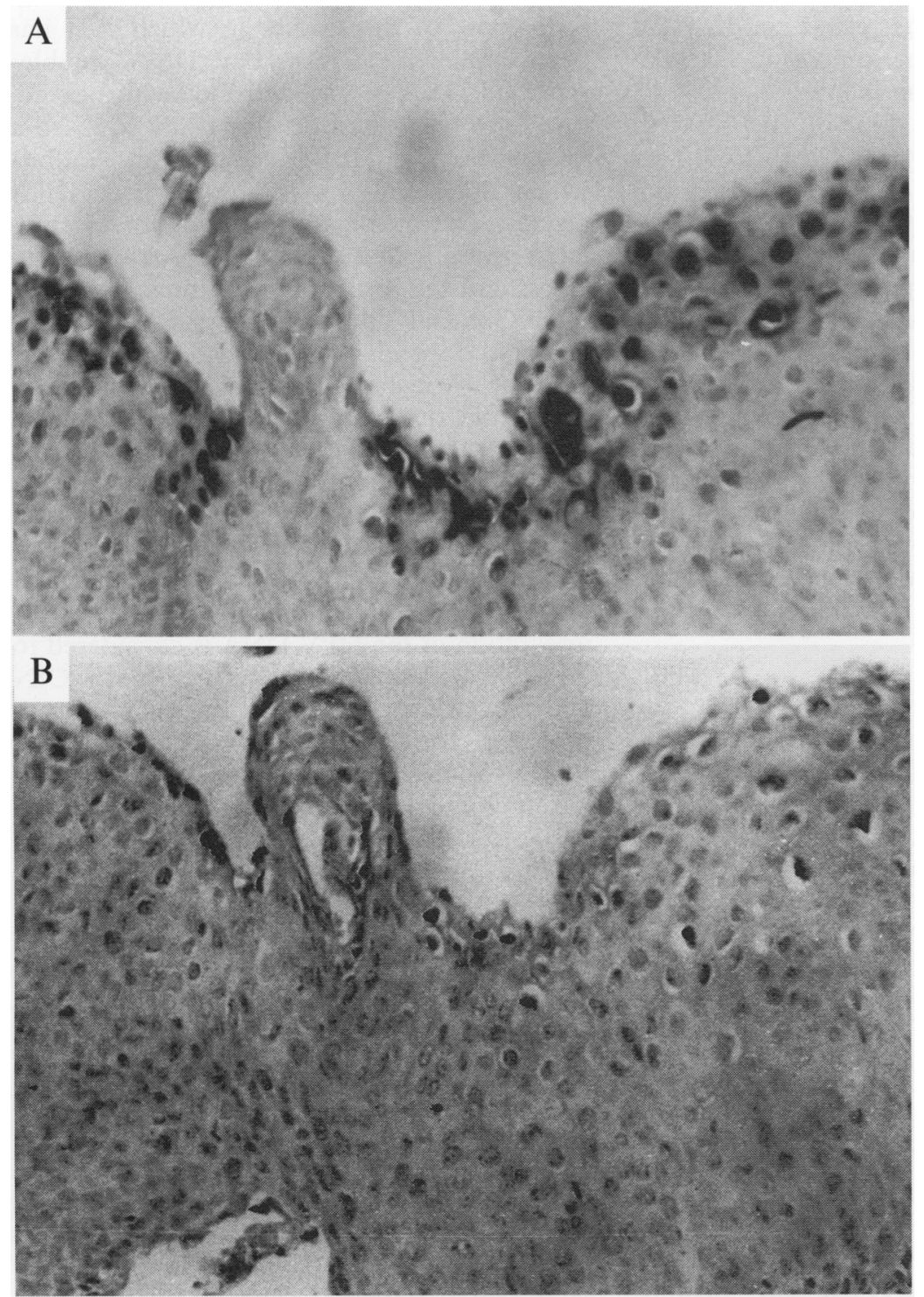

C

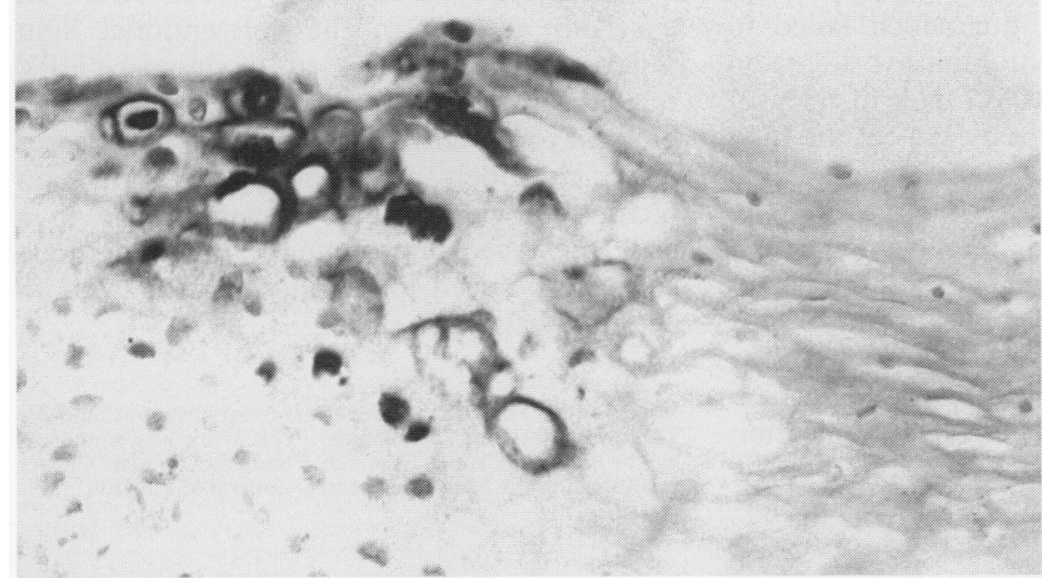

In situ hybridisation (A) HPV 16 in CIN II (case 27); (B) haematoxylin and eosin staining of the same case as in (A); (C) HPV 6/11 in CIN II (case 28). Positive signal is only seen in the uppermost cell layers of the epithelium.

humidified box at $50^{\circ} \mathrm{C}$ overnight, after which the sections were washed with sodium citrate and sodium chloride twice for $5 \mathrm{~min}$ utes each at $60^{\circ} \mathrm{C}$ and once for 5 minutes at room temperature Thereafter, $20-40 \mu 1$ of the detection reagent, included in the test kit, was
Clinical data, histological diagnosis, and NISH results of cases scoring positive for HPV in histology but negative in dot blot hybridisation

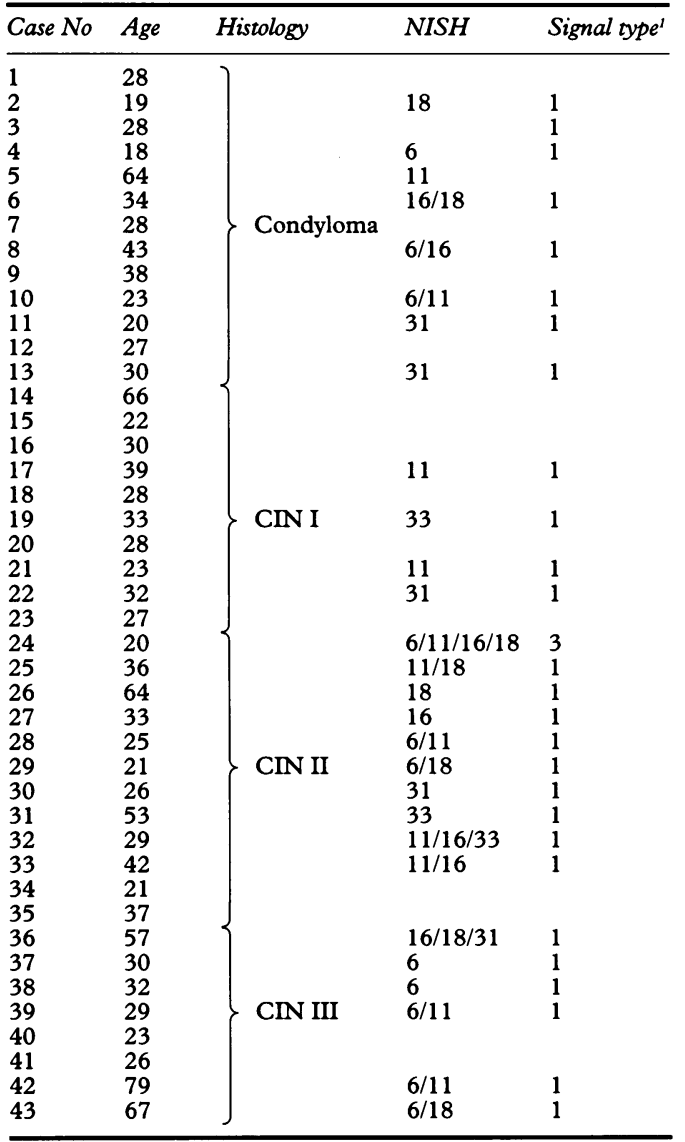

'Signal typing according to Cooper et al, $f$ Clin Pathol 1991;44:990-6.

applied on the sections, followed by washing and incubation with the substrate solution (nitroblue tetrazolium in dimethylformamide and 5-bromo-4-chloro-3-indolylphosphate in dimethylformamide). After washing and dehydration the sections were counterstained with Carbol-Fuchsin and embedded in Permount. As positive controls, cervical samples known to be positive for each of the HPV subtypes tested were used.

The morphologically different NISH signals were categorised as follows ${ }^{7}$ : type 1, a diffuse intranuclear signal, representing episomal replication; type 2, a dot-like nuclear signal, representing integrated DNA; type 3, a combination of types 1 and 2, representing a combination of episomal and integrated DNA.

\section{Results}

Originally 304 cervical, vaginal, and vulvar samples from 267 women were studied for lower genital tract HPV infection by using colposcopy, cytology, histology, and filter DNA hybridisation. Forty three cases were selected for this study, which showed the histological hallmarks of HPV infection but which yielded negative results in the dot blot hybridisation.

The histological diagnosis and the pertinent clinical data of the 43 cases are presented in the table. 
NISH confirmed the presence of HPV DNA in $28(65 \%)$ of the samples in the various diagnostic groups as follows: eight of 13 $(61.5 \%)$ in condyloma, four of $10(40 \%)$ in CIN I, 10 of $12(83.3 \%)$ in CIN II, and six of eight (75\%) in CIN III. Twenty six of the HPV positive cases by NISH (96\%) presented with type 1 signal. Type 3 signal was found in one case representing a CIN II lesion with HPV types 6/11/16/18. Type 2 signal was not found in any of the cases.

Fig 1A shows typical NISH results with HPV 16 probe. Fig $1 \mathrm{C}$ shows a result with type $6 / 11$ probe. Usually, only a few cells showed a positive hybridisation signal, indicating the presence of only a small amount of HPV DNA in the lesions. Fig 1B shows the haematoxylin and eosin staining of the same lesion as in fig $1 \mathrm{~A}$.

\section{Discussion}

During the past few years several recombinant DNA-based techniques have been developed which facilitate the detection of specific HPV DNA in tissue samples and which can be used as an additional means to the classic histopathological analysis to detect HPV infection. Southern hybridisation has proved a sensitive technique for detecting HPV DNA in $95 \%$ of patients with condylomata or CIN. ${ }^{89}$ It has, however, a severe limitation in that it does not allow for a simultaneous assessment of the morphological alterations associated with the lesion. This problem is overcome with an ISH technique which combines a high sensitivity and genotyping of the HPV DNA with a histological evaluation of the lesion. In various studies ISH has proved highly sensitive and specific, but yielding widely differing detecting rates, depending on the types of specimens and the methods used. ${ }^{10-13}$

We used ISH to detect HPV DNA in lesions in which histological analysis showed signs of HPV infection but which failed to score positive in the dot blot hybridisation tests. NISH detected HPV DNA in $65 \%$ of these cases. It was present in $75 \%$ of the high grade, in $83.3 \%$ of the moderate grade, in $40 \%$ of the low grade dysplasias, and in $61.5 \%$ of condylomata. There seems to be a clear correlation between a diminishing detection rate of HPV infection by filter DNA hybridisation and the grade of dysplasia, as has been found in other studies, and which has been assigned to a lack of viral replication in less differentiated epithelial cells. ${ }^{14}$

One obvious explanation for the discordance between the results of the histological and filter DNA hybridisation techniques is the highly subjective nature of the histological assessment of the lesions suspicious of HPV. The histological signs of HPV may be difficult to interpret. Perinuclear halos and nuclear atypia have been found to be only suggestive of $\mathrm{HPV}^{15}$. In fact, more subtle changes, such as nuclear engorgement and irregularity in superficial epithelium seem to be better markers for HPV than the "classical" perinuclear clearing. ${ }^{16}$
In most of the studies in which ISH has been applied to detect HPV DNA, doublestranded DNA probes and radioactive detection have been used. In this study we used a non-radioactive HPV detection kit (Biohit) which is based on biotin-labelled DNA probes. The major advantage of the biotinylated probe is that the morphology is easy to assess and the background staining is negligible. ${ }^{17}$ Generally, the sensitivity of ISH is variable and depends on whether DNA-DNA or DNA-RNA hybrids or radioactive or nonradioactive detection system are used, and on the detection system applied. ${ }^{18-21}$

Application of the ISH signal categorising system by Cooper et $a l^{6}$ indicated episomal replication in most of the cases. There was only one CIN II case with a signal morphology suggestive of HPV integration. Usually, integration of the HPV DNA is considered to be associated only with the high grade CIN and carcinomas. It has also been observed, however, in milder dysplasias. ${ }^{22}$

It is considered that a positive signal in ISH requires a higher copy number of viral particles than in Southern hybridisation. ${ }^{23} 24$ More quantitatively, the sensitivity of ISH has been estimated to be 20 to 40 DNA copies a cell when frozen sections and biotinylated probes are used. ${ }^{25}$ In cervical lesions with a noticeable degree of dysplasia, however, filter hybridisation seems to be less sensitive than ISH with biotinylated probes. ${ }^{23}$ In the present study NISH also yielded positive results in cases which remained negative in filter hybridisation. This can be explained on two counts. First, in ISH a signal can be detected from only a few cells which have a sufficiently high copy number. The same samples may remain negative in filter hybridisation because the detection limit of the dot blot hybridisation refers to an average copy number among all the cells in the sample.

NISH with biotinylated probes offers an excellent adjunct to the conventional light microscopy that helps to distinguish HPV related lesions from non-viral lesions. It can be used to reveal HPV infection even in cases in which widely used dot blot hybridisation techniques yield negative results. Due to a well preserved morphology, this technique can also be used for quality control ${ }^{26}$ and to sharpen diagnostic skills.

We thank Ms Hilkka Penttinen for secretarial support and $\mathrm{Mr}$ Taplo Leinonen for photography. This work was supported by the Finnish Cancer Research Fund, the Finnish Cancer Institute, and the Medical Research Council of Finland.

1 Pfister $\mathrm{H}$. Human papillomaviruses and genital cancer. Adv Cancer Res 1987;48:113-47.

2 Crum CP, Mitao M, Levine RU, Silverstein SJ. Cervical papillomaviruses segregate within morphologically distinct precancerous lesions. $\mathcal{F}$ Virol 1985;54:675-81.

3 DeVilliers E-M. Heterogeneity of the human papillomavirus group. $\mathcal{F}$ Virol 1989;63:4898-903.

4 Syriänen KJ. Epidemiology of human papillomavirus HPV) infections and their association with genital squamous cell cancer. Acta Pathol Microbiol Immunol Scand 1989;97:957-70.

5 Campion MJ, McCause DJ, Cuzick J, Singer A Progressive potential of mild cervical atypia: prospective cytologic, colposcopic and virological study. Lancet 1986;ii: $237-40$. 
6 Cooper K, Herrington CS, Graham AK, Evans MF, McGee JOD. In situ HPV genotyping of cervical intraepithelial neoplasia in South African and UK patients: evidence for putative HPV integration in vivo. f Clin Pathol 1991;44:400-5.

7 Ferenczy A, Winkler B. Cervical intraepithelial neoplasia and condyloma. In: Kurman RJ, ed. Blaustein's pathology of the female genital tract. 3rd edn. New York: ogy of the female genital tract.

8 Boshart M, Gismann L, Ikenberg H, Kleinheinz A, Scheurlen $W$, zur Hausen $H$. A new type of papillomavirus DNA, its presence in genital cancer biopsies and in cell lines derived from cervical cancer. $E M B O \mathcal{F}$ 1984;3:1151-7.

9 Lorinez AT, Temple GF, Kurman RJ, Jenson AB, Lancaster WD. Oncogenic association of specific human papillomavirus types with cervical neoplasia. f NCI 1987;79:671-7.

10 Syrjänen SM, Syrjänen KJ, Mäntyjärvi. Human papillomavirus (HPV) DNA sequences demonstrated by in situ DNA hybridization in serial paraffin-embedded cervical biopsies. Arch Gynecol 1986;239:39-48.

11 Beckmann AM, Myerson D, Daling JR, Kiviat NB, Fenoglio CM, McDougall JK. Detection and localization of human papillomavirus DNA in human genital condylomas by in situ hybridization with biotinylated probes. 9 Med Virol 1985;16:265-73.

12 Gupta J, Gendelman HE, Naghashfar Z, et al. Specific identification of human papillomavirus type in cervical smears and paraffin sections by in situ hybridization with radioactive probes: A preliminary communication. Int $\mathcal{F}$ Gynecol Pathol 1985;4:211-8.

13 Wilbur DC, Reichman RC, Stolier MH. Detection of infection by human papillomavirus in genital condyloinfection by human papillomavirus in genital condylomata. A comparison study using immunocytochemistry and in situ nucleic

14 Syrjänen SM, von Krogh G, Syrjänen KJ. Detection of human papillomavirus DNA in oncogenital condylomata in men using in situ DNA hybridization applied to paraffin sections. Genitourin Med 1987;21:53-89.

15 Nuovo GJ, Nuovo MA, Cottral S, Gordon S, Silverstein SJ, Crum CP. Histological correlates of clinically occult human papillomavirus infection of the uterine cervix. Am f Surg Pathol 1988;12:198-204.

16 Mittal KR, Demopoulos RI. Sensitivity and specificity of various morphological features of cervical condylomas. An in situ hybridization study. Arch Pathol Lab Med 1990;114:1038-41

17 Grussendorf-Conen EI, Cremer S. The demonstration of human papillomavirus 16 genomes in the nuclei of genital cancer using two different methods of in situ genital cancer using two different
hybridization. Cancer 1990;65:283-91.

18 Levi JE, Delcelo R, Alberti VN, Tortoni H, Villa LL. Human papillomavirus $D N A$ in respiratory papillomatoHuman papillomavirus DNA in respiratory papillomatosis detected by in situ hybridization and polym
chain reaction. Am f Pathol 1989;135:1179-84.

19 Holm R, Karlsen F, Nesland JM. In situ hybridization with nonisotopic probes using different detection systems. Modern Pathol 1992;5:315-9.

20 Niedobitek G, Finn T, Herbst $H$, Stein $H$. In situ hybridization using biotinylated probes. An evaluation of different detection systems. Pathol Res Pract 1989; 184:343-8.

21 Stoler $M-H$, Broker TH. In situ hybridization detection of human papillomavirus DNAs and messenger RNAs in human papillomavirus DNAs and messenger RNAs in genital condylomas and

22 Shimoda $K$, Lancaster WD. Integration of HPV DNA sequences in mild cervical dysplasia. Cancer Cell 1987; 5:349-57.

23 Nuovo GJ, Richart RM. A comparison of slot blot. Southern blot and in situ hybridization analyses for human papillomavirus DNA in genital tract lesions. Obstet Gynecol 1989;74:673-8.

24 Walboomers JMM, Nelchers WJG, Mullink $\mathrm{H}$, et al. Sensitivity of biotinylated probes of human papillomavirus type 16 DNA in frozen tissue sections of squamous cell carcinoma of the cervix. Am $\mathcal{F}$ Pathol squamous cell carcin

25 DeVilliers EM, Schneider A, Miklow H, et al. Human papillomavirus infection in women with and without papillomavirus infection in women with and witho

26 Richart RM, Nuovo GJ. Human papillomavirus DNA in situ hybridization may be used for the quality control of genital tract biopsies. Obstet Gynecol 1990;75:223-6. 